\title{
Management of post-radiation therapy complications among prostate cancer patients: A case series
}

\author{
Ryan Kendrick Flannigan, MD; ${ }^{*}$ Richard John Baverstock, MD, FRCSC ${ }^{+}$
}

*Department of Urologic Sciences, University of British Columbia, Vancouver, BC; †Vesia Alberta Bladder Centre, Southern Alberta Center of Urology, University of Calgary, Calgary, AB

Cite as: Can Urol Assoc J 2014;8(9-10):e632-6. http://dx.doi.org/10.5489/cuaj.492

Published online September 9, 2014.

\section{Abstract}

Introduction: Treating prostate cancer with radiation therapy (RT) is a viable option, albeit with its own profile of complications. We describe a unique Canadian report of a single surgeon (RJB) experience in the management of complex post-prostate cancer RT complications.

Methods: We retrospectively analyzed patients who had previously received external beam radiation (XRT) or brachytherapy (BT) for prostate cancer referred to a single surgeon for persistent urologic related difficulties between 2005 and 2010. We used the Radiation Therapy Oncology Group (RTOG) morbidity grading system to assign each patient a 1 to 5 grade for their greatest complication. Results: In total, 15 patients were identified with a total of 43 RT-related complications. Of these 43 complications, 19 presented with obstruction, 8 with radiation failure or new bladder cancer, 6 with hematuria, 5 with intractable incontinence, and 5 with urinary tract infections. These patients required several investigations prior to treatment. Treatment of these complications used surgical, local and medical approaches. In the end, 1 patient had total incontinence, 3 improved their incontinence, 3 had self-catheterization and dilation, 1 voided well, 3 underwent cystectomy with ileo-conduits, 2 had chronic hematuria, and 2 passed away.

Conclusion: These patients are heavily investigated and require significant resources, including patient visits, diagnostics and treatment modalities to optimize their condition. Cure is not always possible, but the aim to improve quality of life should guide management.

\section{Introduction}

Localized prostate cancer, accepted as T1-T2, N0 and M0 disease, is successfully treated using several modalities. The American Urology Association (AUA) identifies and recommends 4 localized therapies: active surveillance (AS), radical prostatectomy $(\mathrm{RP})$, external beam radiation (XRT) and brachytherapy (BT) for localized prostate cancer. ${ }^{1}$ Each treatment modality has evidence to support its use and each has unique potential complications.

We describe a unique Canadian report of a single surgeon (RJB) experience in the management of complex postprostate cancer radiation therapy (RT) complications.

\section{Brachytherapy}

In $\mathrm{BT}$, radioactive seeds are inserted into the prostate transperineally under guidance of a transrectal ultrasound. Typically, they produce 120 to $140 \mathrm{~Gy}$, and have a dose fall-off of about $3 \mathrm{~mm} .^{2}$ Due to the close proximity of the neurovascular bundles, brachytherapy has been associated with a 5-year potency rate of $76 \% .^{3}$ Urethral related complications, namely strictures, have been reported in $1.8 \%$ of patients receiving BT. ${ }^{4}$ Other urinary complications include fistulas and bladder neck contractures. ${ }^{5-8}$

\section{External beam radiation therapy}

XRT typically delivers 60 to 80 Gy to the prostate guided by computed tomography. Despite image-guided therapy, normal peri-prostatic tissue (notably the bladder, rectum, seminal vesicles) and tissues associated with erections are still exposed to radiation. The dose of radiation is positively correlated with a disease-free state, but is associated with more rectal complications. These complications often present later than those seen with RP. Urinary complications have been reported to range between $3.2 \%{ }^{10}$ and $23 \%,{ }^{11}$ including urgency, frequency, hematuria and decreased bladder size. Sexual dysfunction has been described to increase with time and range between $39 \%$ and $64 \%$ at 5 years. ${ }^{12-14}$

The incidence of secondary solid pelvic organ malignancies, including rectal sarcomas and bladder cancers, increases with time. The incidence of developing a bladder cancer post-XRT for prostate cancer is about 6\%; the bladder 
cancer associated with XRT tends to be higher grade and carry higher cause-specific mortality compared to cancers not associated with RT (3.7\%). The latency period can range from 5 to 15 years. ${ }^{15-20}$

\section{Radiation effect on local tissue}

Radiation causes damage to cellular components and DNA. This leads to cell death after the first, or first few cycles of cellular division, ${ }^{21}$ via arrest of mitosis secondary to damage to the cells chromosomes. ${ }^{22}$

XRT does not only target malignant cells, but also adjacent normal tissue. This radiation injury can be classified as acute, including those acquired during the course of treatment; consequential, including those weeks to months after exposure; late, including effects months to years after radiation exposure. ${ }^{23,24}$ Significant acute effect of radiation on local tissue does not predict late effects. ${ }^{25}$

Acute effects lead to upregulation of inflammatory mediators, fibrotic cytokines, activation of the coagulation cascade, as well as vascular injury. ${ }^{26-31}$ Late effects include fibrosis, necrosis, atrophy, vascular damage and increased carcinogenesis. ${ }^{23}$ These factors lend surgically to decreased tissue elasticity, poor mobilization and slow healing. ${ }^{32}$ Clinical correlation exists, as there are reports of increased incidence of comorbidities in surgical procedures following RT. ${ }^{33,34}$

\section{Management of radiation-induced complications}

Radiation can induce acute and chronic morbidity. Conservative therapy is typically supported for managing acute changes, including dysuria, frequency, urgency and mild hematuria. Late complications, however, are more challenging. ${ }^{35}$ In one series, patients with obstructive voiding symptoms secondary to urethral strictures were initially managed with urethral dilatations, visual internal urethrotomies and balloon dilatation. Among the patients that failed this management, urethroplasties were performed. Half of the patients became incontinent and 4 went on to receive artificial urinary sphincters. ${ }^{36}$ Kollmeier and colleagues reported their results of performing transurethral resections (TURPs) on 38 post-BT patients presenting with urinary retention; $18 \%$ were initially incontinent, and this number increased to $36 \%$ after 2 years post TURP. ${ }^{37}$ Among patients presenting with urinary fistulas post-RT, one study reports their management consisting of initial fecal diversion by colostomy or ileostomy in $81 \%$ of cases with a trial of bladder drainage by Foley catheter; unfortunately, $82 \%$ of these patients had to undergo subsequent cystectomy and urinary diversion.? Moreira and colleagues managed RT-induced fistulas via urinary diversions with the addition of dartos, omental or gracilis flaps to close the fistulas, and had favourable outcomes. ${ }^{8}$ Patients with post-RT prostatic strictures and bladder neck contractures were treated based on patient preference, ranging from intermittent or indwelling catheters to transurethral incisions and resections.

\section{Methods}

Patients previously receiving XRT or BT with urologic difficulties between 2005 and 2010 were retrospectively analyzed. A review of full hospital and clinic electronic medical records was done. Patients with acute complications related to RT were not included in this study and thus only late complications defined as those occurring more than 90 days after RT were discussed. Only those patients being referred for persistent and complex urologic opinion during the specified time period were included for a singlesurgeon Canadian experience. Each patient's complications were stratified according to the Radiation Therapy Oncology Group (RTOG) morbidity grading system and the maximum complication grade was applied..$^{38}$ This study excluded patients with simple stress incontinence after radiotherapy or BT.

\section{Results}

In total, 15 patients were identified, with a mean age of 68.9 (range: $51-84$ ). Among these patients, 43 complications requiring specific management were addressed. Ten patients with previous XRT accounted for 27 complications and 5 patients with previous BT accounted for 16 complications.

Patient visits were recorded. Given the complex nature of these patients, often multiple complications were present in patients and resultant complications secondary to therapeutic intervention were present in others. Each patient on average was seen nearly 9 times (range: $3-17$ ) during the study period, for a total of 131 visits. This only includes visits with a single surgeon (RJB) or investigations ordered by this same surgeon. It does not include other healthcare visits for these complications to emergency, homecare visits for catheter issues, or visits to prescribed hyperbaric oxygen therapy (HBOT).

\section{Diagnosis}

Complications were classified based upon type of symptom for which the patient was referred (Fig. 1). Complications were stratified among the RTOG morbidity grading system and the maximum complication grade was applied (Table 1).

\section{Management}

These complications required several investigations during the time course of this study. All patients had received serum prostate-specific antigen tests. Of the total complications, 34 
required cystoscopy, with most men requiring more than one cystoscopy; 4 required urodynamic investigations (UDS), 1 required computed tomography $(\mathrm{CT}), 1$ required prostatic biopsy.

Treatment modalities for these complications were organized into 3 categories: medical, local and surgical management (Table 2). Surgical therapy was considered an intervention requiring some form of anesthetic. Local therapy involved treatments of the genitourinary tract not requiring formal anesthetic (e.g., dilatation and catheterization) and medical therapy involved treatment using medications.

At the conclusion of the study period, $1(7 \%)$ patient continued to have total incontinence; 3 (20\%) patients lived with improved incontinence ( $<1$ pad per day); $3(20 \%)$ patients self-catheterized and dilated ( 1 due to an atonic bladder and 2 for recurrent structuring); 1 (7\%) patient reported voiding well; $3(20 \%)$ patients underwent cystectomy with ileo-conduits; 2 (13\%) patients had chronic hematuria; and $2(13 \%)$ passed away (1 from comorbid medical disease and 1 from a pulmonary embolus a week before the scheduled cystectomy).

\section{Discussion}

The 15 patients in the present case series presented with 43 total complications. Often, these patients had several complications upon presentation, including obstructive symptoms due to stricturing with recurrent UTIs and hematuria. Obstructive complaints were the most common and a variety of etiologies were responsible. Urethral strictures were the most common diagnosis and often required manipulative surgical therapy. However, in the case of one individual with obstructive symptoms, TURP for prostatic obstruction led to urinary incontinence following the procedure. Without obvious operator error, this event could potentially be attributed to local tissue changes, fibrin deposition and atrophy resulting in reduced function of the sole remaining external urinary sphincter following the resection. ${ }^{39-42}$ Some tissue obstruction may contribute to continence, and therefore particular caution should be taken when resecting radiated prostatic tissue. Rectal injury has often been feared in the setting of a post-BT patient requiring a TURP. These patients, although not common, are some of the most feared referrals in urology and are likely best managed by a small, consistent group of tertiary urologists.

Most patients presenting with hematuria, were secondary to malignancy of the bladder or prostate. However, radiation cystitis and non-specific cystitis also presented several times. Surgical management was predominately used, however attempts of intravesical therapy were used with epirubicin and BCG to manage the superficial bladder cancer. HBOT is presently being utilized in 1 patient to promote bladder healing. In severe cases, cystectomy with ileal conduit is the last resort, and sometimes necessary to provide relief of the complications and improve quality of life.

Among the 4 cases of recurrent prostate cancer, it is not possible to determine whether these cases were recurrence of the original tumour or if radiation exposure led to secondary tumour formation. The former is likely true, however the unique characteristics of RT lending to genetic instability and previously reported secondary pelvic tumours make the argument less than dissmissable. ${ }^{15-19}$ More convincing for the latter argument include 2 patients that developed recurrent bladder. After failed TURBT, BCG and epirubicin, radical cystectomy with ileal loop conduits were performed. Determining whether these episodes of bladder cancer were primary, or secondary to radiation is difficult, but both are certainly plausible.

Surgical therapy accounted for about $50 \%$ of the management for complications related to hematuria, obstruction and local cancer. However, local therapy and/or medical management was more appropriate for some patients as

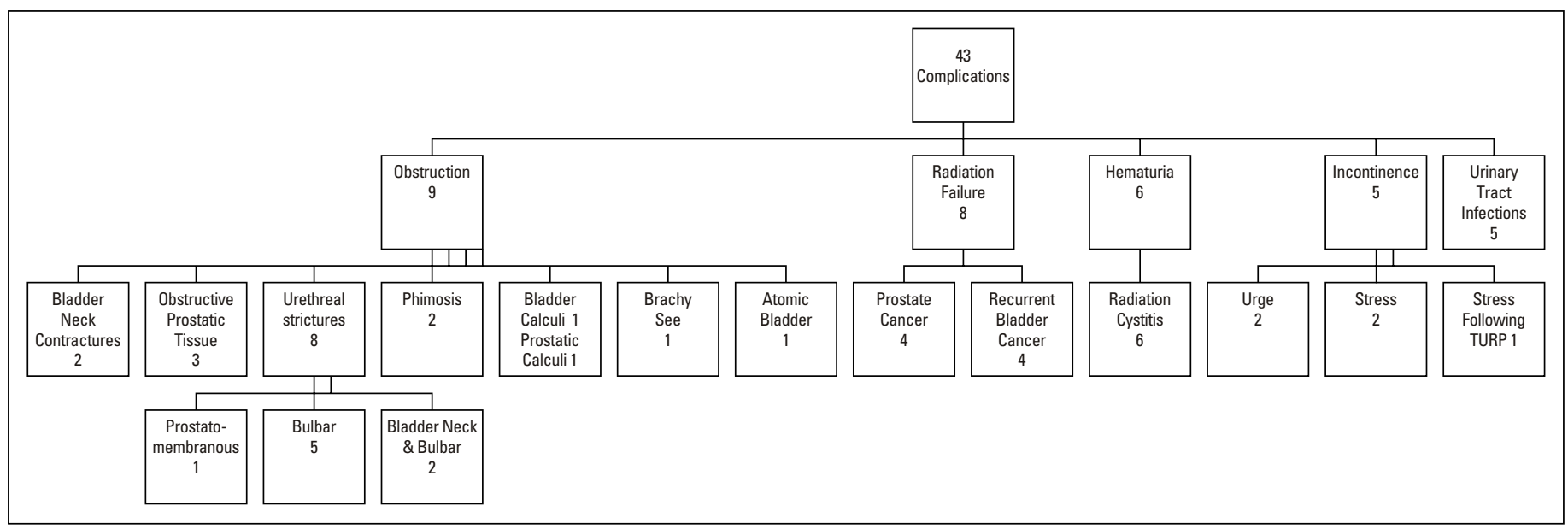

Fig. 1. Complication defined by classification and etiology. 


\begin{tabular}{|c|c|c|c|c|c|}
\hline & RTOG grade 1 & RTOG grade 2 & RTOG grade 3 & RTOG grade 4 & RTOG grade 5 \\
\hline $\begin{array}{l}\text { Maximum } \\
\text { morbidity }\end{array}$ & - & - & $\begin{array}{l}\text { Cystoscopy and grasping forceps }(n=1) \\
\text { Cystoscopy and dilatation }(n=1)\end{array}$ & $\begin{array}{c}\text { GLL }(n=2) \\
\text { TURP }(n=4) \\
\operatorname{VIU~}(n=3) \\
\text { Cystectomy }(n=2) \\
\text { Laser lithopaxy }(n=1)\end{array}$ & $\begin{array}{l}\text { Death due } \\
\text { to PE }\end{array}$ \\
\hline Total no. patients & 0 & 0 & 2 & 12 & 1 \\
\hline
\end{tabular}

surgery in this patient population is technically challenging due to poor tissue mobilization, decreased elasticity and poorer wound healing properties. ${ }^{32}$
Competing interests: Dr. Flannigan declares no competing financial or personal interests. Dr. Baverstock is a member of the Advisory Boards for Astellas, Pfizer and Allergan. He is also a member of the Speakers Bureau for Astellas, Pfizer, Allergan and AMS. He has received grants from Astellas, Pfizer and Allergan and is currently participating in a clinical trial on behalf of Pfizer and Allergan.

\section{Conclusion}

Evaluating complications usually requires going beyond his-

This paper has been peer-reviewed. tory and physical examination. Cystoscopy is common; however, urodynamic studies, CT and biopsy are also necessary in some circumstances. Utilization of these resources, although necessary, burdens the healthcare system in terms of cost and availability. Managing these complications accrue costs from acute and long-term management, as well as investigations above and beyond the original resources used in the initial RT. It requires patience on the part of the urologist and the patient, as well as access to multimodal therapies, such as HBOT and onabotulinum toxin. Long-term follow-up and ongoing management are necessary to optimize these patients' symptomatology. From the outset, the patient needs to be aware that these are difficult problems to treat and a cure may not be possible, but management through multiple visits and manipulative procedures may be necessary. Most patients are not cured of their complication, but rather managed by the best available tools and expertise of their urologist.

\section{References}

1. Thompson I, Thrasher IB, Aus G, et al. AUA Guideline for the Management of Clinically Localized Prostate Cancer: 2007 Update. http://www.auanet.org/common/pdf/education/clinical-guidance/ProstateCancer.pdf. Accessed July 30, 2014.

2. D'Souza WD, Thames HD, Kuban DA. Dose-volume conundrum for response of prostate cancer to brachytherapy: Summary dosimetric measures and their relationship to tumor control probability. Int I Radiat Oncol Biol Phys 2004;58:1540.

3. Potters Ll, Torre T, Fearn PA, et al. Potency after permanent prostate brachytherapy for localized prostate cancer. Int J Radiat Oncol Biol Phys 2001;50:1235-42.

4. Elliott SP, Meng MV, Elkin EP, et al. Incidence of urethral stricture affer primary treatment for prostate cancer: Data from CaPSURE. J Urol 2007; 178:529.

5. Shakespeare D, Mitchell DM, Carey BM, et al. Recto-urethral fistula following brachytherapy for localized prostate cancer. Colorectal Dis 2007;9:328-31.

6. Sarosdy MF. Urinary and rectal complications of contemporary permanent transperineal brachytherapy for prostate carcinoma with or without external beam radiation therapy. Cancer 2004;101:754-60.

7. Chrouser KL, Leibovich BC, Sweat SD, et al. Urinary fistulas following external radiation or permanent brachytherapy for the treatment of prostate cancer. J Urol 2005;173:1953-7.

\section{Table 2. Treatment by type of complication}

\begin{tabular}{|c|c|c|c|c|}
\hline Obstruction & Hematuria & $\begin{array}{l}\text { Superficial } B C \text { and } \\
\text { radiation failure }\end{array}$ & Incontinence & $\begin{array}{l}\text { Recurrent UTI and } \\
\text { prostatitis }\end{array}$ \\
\hline $\begin{array}{l}\text { Surgical therapies }(n=15) \\
\text { Seed removal }(n=1) \\
\text { Bladder stone }(n=2) \\
\text { GLL }(n=3) \\
\text { TURP }(n=3) \\
\text { Circumcision for phimosis }(n=2) \\
\text { VIU }(n=4)\end{array}$ & $\begin{array}{l}\text { Surgical therapies } \\
\qquad(n=4) \\
\text { TURP }(n=2) \\
\text { TuRiS }(n=1) \\
\text { GLL }(n=1)\end{array}$ & $\begin{array}{c}\text { Surgical therapies }(n=8) \\
\text { TURBT }(n=4) \\
\text { Cystectomy }(n=2) \\
\text { Radiation Tx }(n=1)^{* * *} \\
\text { TURP }(n=1)\end{array}$ & $\begin{array}{c}\text { Surgical therapy }(n=1) \\
\text { Botox }(n=1)\end{array}$ & $\begin{array}{l}\text { Surgical therapy } \\
\qquad(\mathrm{n}=0)\end{array}$ \\
\hline $\begin{array}{l}\text { Local management }(n=12) \\
\text { Urethral dilation }(n=8) \\
\text { Self-dilation }(n=4)\end{array}$ & $\begin{array}{l}\text { Local management } \\
\qquad(n=1) \\
\text { Indwelling }(n=1)\end{array}$ & $\begin{array}{l}\text { Local management } \\
\qquad(\mathrm{n}=0)\end{array}$ & $\begin{array}{c}\text { Local management }(n=5) \\
\text { Self-catheterization }(n=2) \\
\text { Pads }(n=1) \\
\text { Indwelling }(n=2)\end{array}$ & $\begin{array}{l}\text { Local management } \\
\qquad(\mathrm{n}=0)\end{array}$ \\
\hline $\begin{array}{l}\text { Medical therapies }(n=5) \\
5 \text {-ARls }(n=3) \\
\text { Alpha-antagonist }(n=2)\end{array}$ & $\begin{array}{l}\text { Medical therapies } \\
\qquad(n=3) \\
\text { 5-ARIs }(n=3)\end{array}$ & $\begin{array}{l}\text { Medical therapies }(n=7) \\
\text { Epirubicin }(n=2) \\
\text { BCG }(n=1) \\
\text { HRT }(n=4)\end{array}$ & $\begin{array}{l}\text { Medical therapies }(n=6) \\
\text { Low-dose antibiotics }(n=1) \\
\text { Anticholinergic }(n=4) \\
\text { O \& B }(n=1)\end{array}$ & $\begin{array}{l}\text { Medical therapy } \\
\quad(n=5) \\
\text { Antibiotics }(n=5)\end{array}$ \\
\hline
\end{tabular}

BC: bladder cancer; UTI: urinary tract infection; GLL: GreenLight laser; TURP: transurethral resection of the prostate; VIU: visual internal urethrotomy; TURiS: Transurethral resection in saline; TURBT: transurethral resection of the bladder tumour; Tx: therapy; ARI: alpha-reductase inhibitors; BCG: Bacillus Calmette-Guerin; HRT: hormone replacement therapy; O \& B: [AU7: Please expand this acronym.]. ${ }^{* * *}$ One patient with obstructed symptoms post-brachytherapy had an elevated prostate-specific antigen levels and recurrent cancer; he had an open and closed prostatectomy in Toronto, Canada. 
Flannigan and Baverstock

8. Moreira SG Jr, Seigne JD, Ordorica RC, et al. Devastating complications after brachytherapy in the treatment of prostate adenocarcinoma. BJU Int 2004;93:31-5.

9. Pollack Al, Zagars GK, Starkschall G, et al. Prostate cancer radiation dose response: Results of the MD Anderson phase III randomized trial. Int J Radiat Oncol Biol Phys 2002;53:1097-105.

10. Schultheiss TE, Hanks GE, Hunt MA, et al. Incidence of and factors related to late complications in conformal and conventional radiation treatment of cancer of the prostate. Int I Radiat Oncol Biol Phys 1995:32:643-9.

11. Dearnaley DP, Khoo VS, Norman AR, et al. Comparison of radiation side-effects of conformal and conventional radiotherapy in prostate cancer: A randomised trial. Lancet 1999;353:267-72.

12. Talcott JA, Rieker $P$, Clark JA, et al. Patient-reported symptoms after primary therapy for early prostate cancer: Results of a prospective cohort study. J Clin Oncol 1998;16:275-83.

13. Zelefsky MJ, Wallner KE, Ling $\mathrm{CC}$, et al. Comparison of the 5-year outcome and morbidity of threedimensional conformal radiotherapy versus transperineal permanent iodine-125 implantation from earlystage prostatic cancer. J Clin Oncol 1999;17:517-22.

14. Mantz CA, Nautiyal J, Awan A, et al. Potency preservation following conformal radiotherapy for localized prostate cancer: impact of neoadjuvant androgen blockade, treatment technique, and patient-related factors. Cancer I Sci Med 1999:5:230-6.

15. Brenner DJ, Curtis RE, Hall EJ, et al. Second malignancies in prostate carcinoma patients after radiotherapy compared with surgery. Cancer 2000;88:398-406.

16. Boorijan S, Cowan JE, Konety BR,et al. Bladder cancer incidence and risk factors in men with prostate cancer: Results from CaPSURE. J Urol 2007;177:883-7.

17. Bostrom PJ, Soloway MS, Manoharan M, et al. Bladder cancer after radiotherapy for prostate cancer: Detailed analysis of pathological features and outcome after radical cystectomy. J Urol 2008;179:91-5.

18. Shah SK, Lui PD, Baldwin DD, et al. Urothelial carcinoma after external beam radiation therapy for prostate cancer. J Urol 2006;175:2063-6.

19. Neugut Al, Ahsan H, Robinson E, et al. Bladder carcinoma and other second malignancies after radiotherapy for prostate carcinoma. Cancer 1997;79:1600-4.

20. Moon K, Stukenborg G, Keim J, et al. Cancer incidence after localized therapy for prostate cancer. Cancer 2006;107:991-8.

21. Thompson LH, Suit HD. Proliferation kinetics of X-irradiated mouse L cells studied with time-lapse photography. Int J Radiat Biol 1969:15:347-62.

22. Dewey WC, Furman SC, Miller HH. Comparison of lethality and chromosomal damage induced by x-rays in synchronized Chinese hamster cells in vitro. Radiat Res 1970;43:561-81.

23. Stone $\mathrm{H}$, Coleman $\mathrm{CN}$, Anscher MS, et al. Effects of radiation on normal tissue: Consequences and mechanisms. Lancet Oncol 2003;4:529-36.

24. Dörr W, Hendry JH. Consequential late effects in normal tissues. Radiother Oncol 2001;61:223-31.

25. Chu FCH, Glicksman AS, Nickson JJ. Late consequences of early skin reactions. Radiology 1970;94:66972.

26. Dent P, Yacoub A, Contessa J, et al. Stress and radiation-induced activation of multiple intracellular signaling pathways. Radiat Res 2003;159:283-300.
27. Chen Y, Williams J, Ding I, et al. Radiation pneumonitis and early circulatory cytokine markers. Semin Radiat Oncol 2002;12(Suppl 1):26-33.

28. Rubin P, Johnston CJ, Williams JP, et al. A perpetual cascade of cytokines postirradiation leads to pulmonary fibrosis [see comments]. Int J Radiat Oncol Biol Phys 1995;33:99-109.

29. Fu XL, Huang $H$, Bentel $G$, et al. Predicting the risk of symptomatic radiation-induced lung injury using both the physical and biologic parameters V(30) and transforming growth factor beta. Int J Radiat Oncol Biol Phys 2001;50:899-908.

30. Paris F, Fuks Z, Kang A, et al. Endothelial apoptosis as the primary lesion initiating intestinal radiation damage in mice. Science 2001:293:293-7.

31. Hauer-Jensen $M$, Kong FM, Fink $L M$, et al. Circulating thrombomodulin during radiation therapy of lung cancer. Radiat Oncol Investig 1999;7:238-42.

32. Mundy AR, Andrich DE. Urorectal fistulae following the treatment of prostate cancer. BJU Int 2010;107:1298-303.

33. Tolhurst SR, Rapp DE, $O^{\prime}$ Connor $C$, et al. Complications after cystectomy and urinary diversion in patients previously treated for localized prostate cancer. Urology 2005;66:824-29.

34. Gautam J, Katz MH, Steinberg GD. Radical cystectomy in patients previously treated for localized prostate cancer. J Urol 2010;76:1430-3.

35. Anderson JF, Swanson DA, Levy LB, et al. Urinary side effects and complications after permanent prostate brachytherapy: The MD Anderson Cancer Center experience. J Urol 2009;74:601-5.

36. Meeks JJ, Brandes SB, Morey AF, et al. Urethroplasty for radiotherapy induced bulbomembranous strictures: A multi-institutional experience. J Urol 2011;185:1761-5.

37. Kollmeier MA, Stock RG, Cesaretti J, et al. Urinary morbidity and incontinence following transurethral resection of the prostate after brachytherapy. J Urol 2005;173:808-12.

38. Pilepich MV, Krall JM, Sause WT, et al. Correlation of radiotherapeutic parameters and treatment related morbidity in carcinoma of the prostate-analysis of RTOG study 75-06. Int I Radiat Oncol Biol Phys 1987; $13: 351-7$

39. Hopewell JW. The importance of vascular damage in the development of late radiation effects in normal tissues. In: Meyn RE, Withers HR (Eds). Radiation biology in cancer research. New York: Raven Press; 1980:449-59.

40. Hopewell JW, Young CM. Changes in the microcirculation of normal tissues after irradiation. Int J Radiat Oncol Biol Phys 1978:4:53-8.

41. Fajardo LF. Morphology of radiation effects on normal tissues. In: Perez CA, Brady LW (Eds). Principles and practice of radiation oncology. Second edition. Philadelphia: PA; JB Lippincott Company; 1992:114-23.

42. Vujaskovic $Z$, Anscher $M S$, Feng $Q$, et al. Radiation-induced hypoxia may perpetuate late normal tissue injury. Int I Radiat Oncol Biol Phys 2001;50:851-5.

Correspondence: Dr. Ryan Kendrick Flannigan, Department of Urological Sciences, University of British Columbia, Vancouver, BC; rkflanni@gmail.com 